\title{
Daur Ulang Sampah di Desa Paisbuloli Sulawesi Tenggara
}

\author{
Purnama Pasande*1, Ezra Tari² \\ ${ }^{1}$ Sekolah Tinggi Teologi Star's Lub Luwuk Banggai \\ Institut Agama Kristen Negeri Kupang \\ 1Program Studi Pendidikan Agama Kristen \\ ${ }^{2}$ Program Pascasarjana Magister Pendidikan Agama Kristen

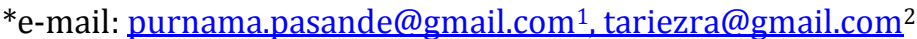

\begin{abstract}
The problem of rubbish begins with the activity of disposal and burning in temporary landfills. The purpose of this service is to provide learning to the community on how to manage waste into plastic clothing; trash exchanged for rubbish, garbage exchanged for vegetables, recycled bags, eco-bricks for eggs, paving blocks, and paintings from used plastic bags. The methods used for waste management are: reducing, reusing, recycling, replanting, and replacing. Community service produces an important thing that is, it still encourages the community to be actively involved in managing waste. It is necessary to involve village officials to move the community to reduce waste. Moreover, there is training for the community to create jobs from waste recycling.
\end{abstract}

Keywords: garbage, environment, recycling

\section{Abstrak}

Problem sampah berawal dari aktifitas pembuangan dan pembakaran di tempat pembuangan sampah sementara. Tujuan dari pengabdian ini adalah memberi pembelajaran kepada masyarakat cara mengelola sampah menjadi baju plastik, sampah ditukar dengan sampah, sampah ditukar dengan sayur, tas daur ulang, eco brick ditukar dengan telur, paving blok, dan lukisan dari kantong plastik bekas. Cara yang digunakan untuk pengelolaan sampah yakni: mengurangi, menggunakan kembali, mendaur ulang, menanam kembali, dan menggantikan. Pengabdian masyarakat menghasilkan hal penting yakni, tetap mendorong masyarakat untuk terlibat aktif dalam mengelola sampah. perlu melibatkan perangkat desa untuk menggerakkan masyarakat mengurangi sampah. Serta adanya pelatihan bagi masyarakat untuk menciptakan lapangan kerja dari daur ulang sampah.

Kata kunci: sampah, lingkungan, daur ulang

\section{PENDAHULUAN}

Sampah merupakan persoalan besar dalam rumah dan lingkungan. Penyelesaian masalah sampah harus menyeluruh dari hulu ke hilir dan seluruh pihak turut terlibat supaya persoalan sampah dapat diatasi (Mahyudin, 2017). Beberapa faktor yang menghambat sistem pengelolaan sampah di Kelurahan Dufa-Dufa adalah kepadatan dan penyebaran penduduk, karakteristik lingkungan, sosial ekonomi, budaya, sikap dan perilaku masyarakat. Pengolahan sampah hendaknya melibatkan berbagai komponen pemangku kepentingan dengan memperhatikan karakteristik sampah serta keberadaan sosial-budaya masyarakat setempat (Sahil et al., 2016).

Penanganan sampah berbasis masyarakat sebenarnya terdapat pada rantai proses di tingkat rumah tangga dan tingkat. Cara penanganan yang dilakukan tersebut bertujuan untuk membudayakan cara pembuangan sampah yang baik mulai dari lingkungan rumah. Sampah yang dikumpulkan terpisah antara sampah organik dan non organik. Setiap kelurahan dapat memanfaatkan sampah organik diolah menjadi kompos (Rijati et al., 2017). Permasalahan sampah masih menjadi persolan yang rumit, bahkan akan tetap menjadi persoalan serius. Oleh karenanya, disarankan kepada pihak terkait (masyarakat, aparat perangkat desa maupun pemerintah daerah) untuk terus secara berkesinambungan dan terpadu untuk mengelola masalah sampah (Dai \& Pakaya, 2019).

Kegiatan daur ulang menurut Kaseva meliputi perbaikan, mendaur ulang, konversi bahan, suku cadang dan produk. Daur ulang sampah membutuhkan pendekatan yang berkelanjutan untuk 
mengelola limbah padat dalam membantu ekonomi masyarakat (Zahra \& Damanhuri, 2011). Kendala pengelolaan sampah menurut Juliandono dalam penelitiannya mengenai pelasanaan Bank sampah di sistem pengelolaan sampah mengemukakan bahwa peran serta nasabah bank sampah sangat rendah dalam pemilahan sampah pada sumbernya (Radityaningrum et al., 2017). Sampah dapat dijadikan sampah komersil atau sampah yang laku dijual untuk dijadikan produk lainnya sehingga apabila diolah lebih lanjut dapat menghasilkan keuntungan. Selain dijual sampah anorganik dapat diolah menjadi barang hiasan rumah tangga, peralatan rumah tangga, dan bahan dalam pembuatan karya seni rupa (Rijati et al., 2017). Pengetahuan cara memilah, memilih dan mencari tempat penampungan, menemukan pembeli dan tempat proses daur ulang sampah yang terkumpul, dan menganalisa hasil penjualan (Purwanto, 2019).

Berikut produksi sampah di desa Paisbuloli, kecamatan Batui Selatan, kabupaten Banggai.

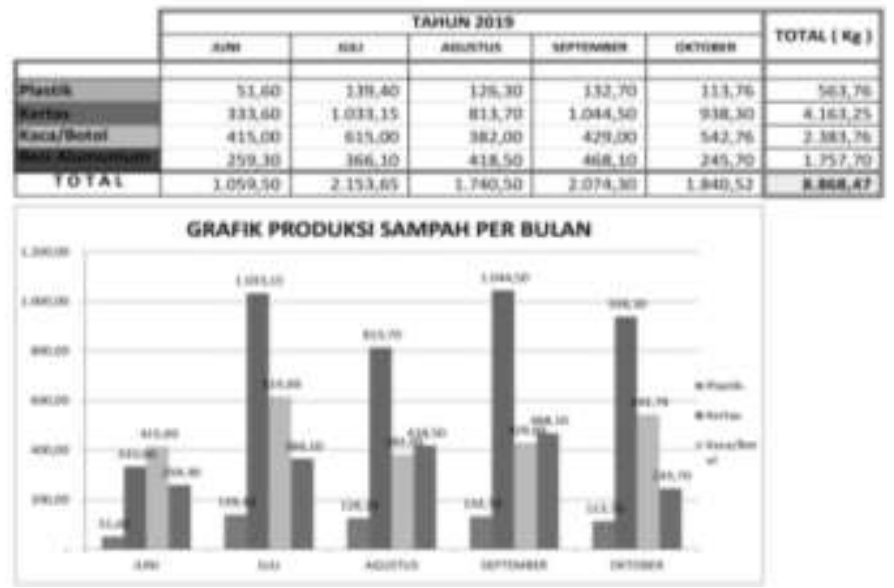

Gambar 1. Produksi sampah

Salah satu contoh dari proses daur ulang yakni: plastik (recycle) yang bertujuan untuk mengubah penggunaan barang plastik supaya tetap bermanfaat, misalnya dengan membuat tas atau produk berguna dan bernilai jual. Salah satu pemanfaatan sampah yakni, paving block dari limbah plastik dan kulit kopi. Paving blok dari sampah plastik dan limbah kulit kopi dapat memberikan dampak positif yang cukup banyak kepada masyarakat. Masyarakat menjadi berfikir ulang apabila mereka ingin membuang sampah di sungai (Luthfianto, 2020). Pelibatan langsung masyarakat untuk berpartisipasi dalam pelatihan pemilahan sampah, yaitu pengetahuan kategorisasi untuk pemilahan sampah (Intan Paradita, 2018).

Masalah yang dihadapi di desa Paisbuloli adalah pertama, biaya operasional (mobilisasi) antar jemput sampah yang cukup tinggi. Kedua, tenaga yang bekerja masih sukarela. Ketiga, fasilitas alat untuk memilah sampah masih sangat sederhana. Keempat, minimnya pengetahuan seluruh pengurus bank sampah Montolutusan mengenai pengelolaan sampah yang baik dan benar hingga menjadi sukses. Kelima, minimnya alat daur ulang sampah (pembuatan tas dan souvenir lainnya). Tujuan dari pengabdian ini adalah mendorong masyarakat untuk terlibat aktif dalam memilah sampah, serta pengelola bank sampah.

\section{METODE}

Pelaksanaan kegiatan pengabdian di desa Paisbuloli, kecamatan Batui Selatan, kabupaten Banggai. Sampah merupakan suatu bahan yang terbuang atau dibuang dari sumber hasil aktivitas maupun proses alam yang belum memiliki nilai ekonomis dan punya dampak negatif yang ditimbulkan yaitu gangguan kesehatan, pencemaran air tanah. Sehingga diperlukan pengelolaan sampah yang baik dan benar melalui Bank Sampah Montolutusan ( BSM ) sehingga tercipta lingkungan yang lebih bersih, Masyarakat yang lebih sehat serta tambahan penghasilan. 
Sistem pengumpulan di lokasi studi adalah individual tidak langsung dimana petugas sampah mengumpulkan sampah dari masing - masing rumah dengan menggunakan gerobak sampah. Penanganan sampah dapat dilakukan baik secara pengolahan dengan teknologi komposter atau pemilihan, di mana sampah yang memiliki nilai ekonomi dapat ditabungkan di bank sampah sehingga dapat meningkatkan perekonomian masyarakat di lokasi studi (Arsyandi et al., 2019).

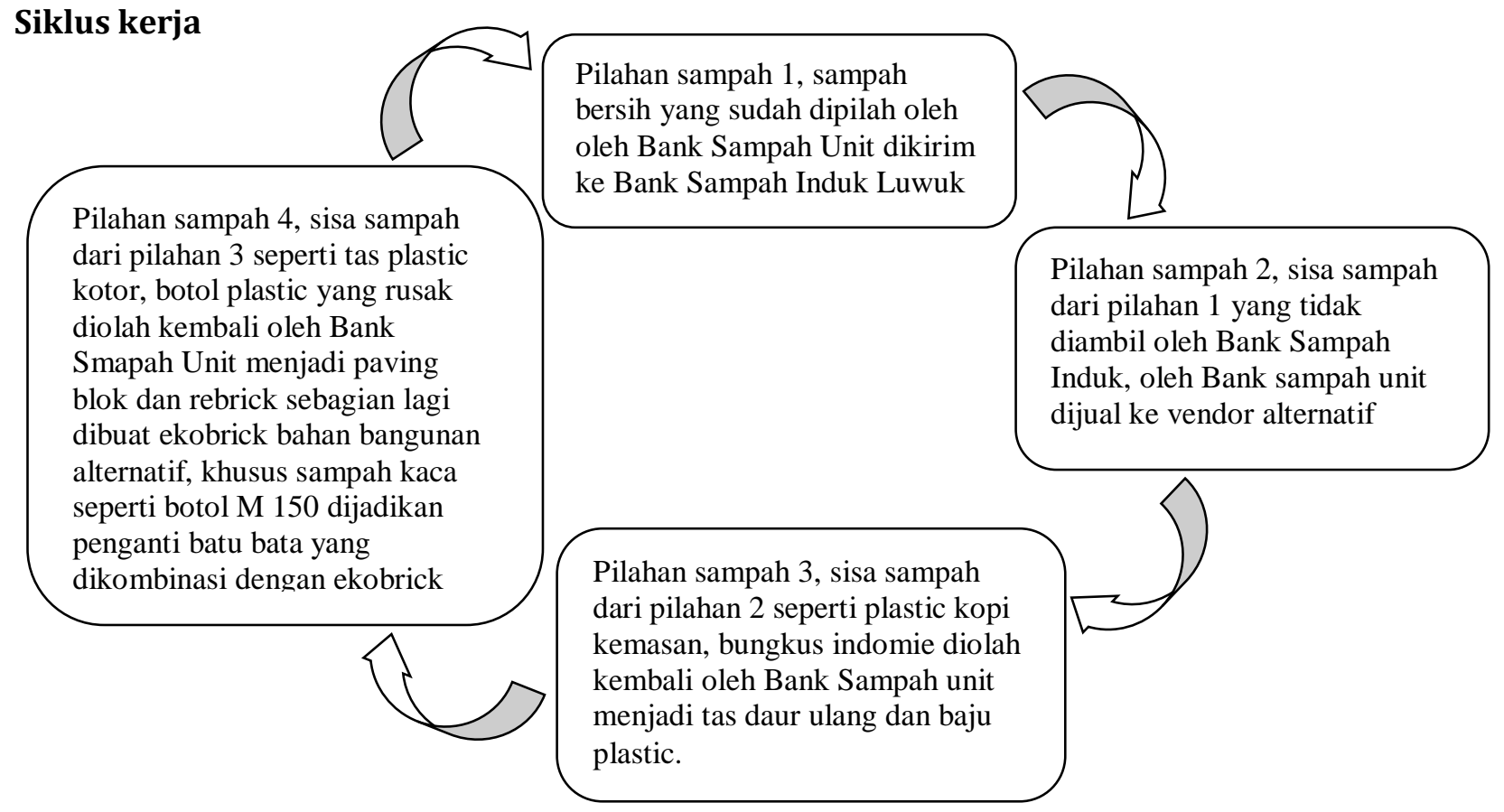

Gambar 2. Pengelolaan sampah

\section{Sosialisasi}

Sosialisasi pengelolaan sampah kepada masyarakat dengan melibatkan seluruh masyarakat yakni: 1) Program dan rencana; 2) Produk yang telah dihasilkan; 3) Pelatihan pemilahan sampah, dan kreasi yang dibuat oleh bank sampah; 4) Pendampingan; 5) evaluasi program. Berikut sosialisasi yang dilakukan bersama personil bank sampah:

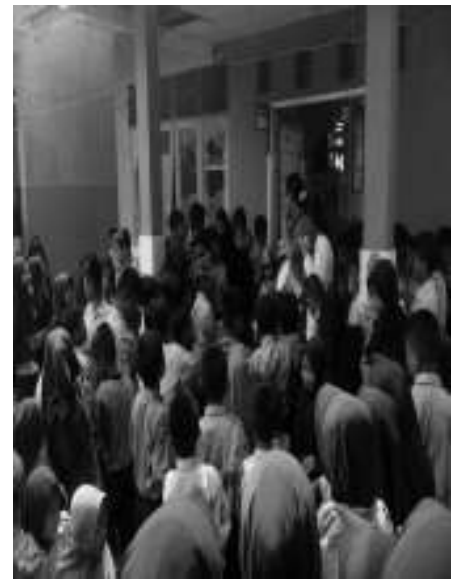

a

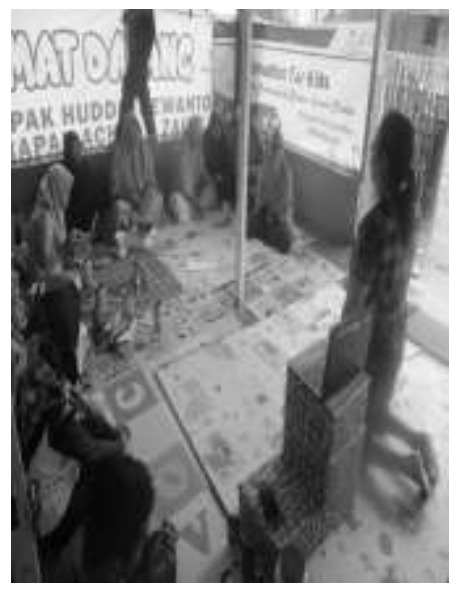

b

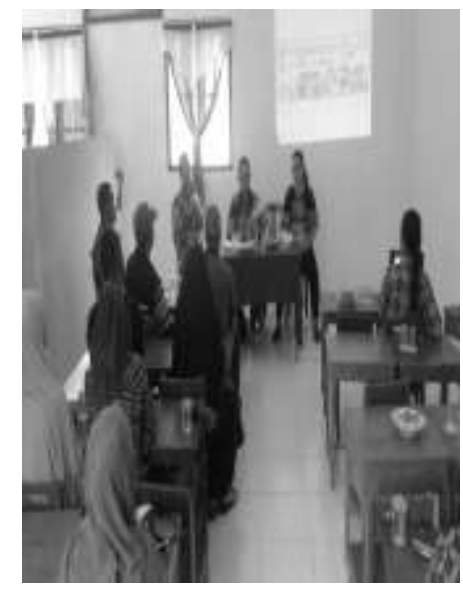

C

Gambar 3. (a) sosialisasi bank sampah di SD Bonebalantak

(b) sosialisasi bank sampah di desa Sinorang

(c) Sosialisasi bank sampah di Desa Sumber harjo 


\section{Metode penjemputan sampah}

Aktivitas penjemputan sampah dengan gerobak, mobil puck up dan dengan truck. Serta sosialisasi kepada warga agar sadar dalam membuang sampah dan mengajak untuk mencintai lingkungan. Pengambilan sampah belum dipisahkan antara basah dan kering. Sampai di lokasi pengolahan sampah, baru dipisahkan.

\section{HASIL DAN PEMBAHASAN}

Bank sampah membuat karya yang luar biasa hasil kerjasama dari beberapa yang kerja itu di bank sampah. Berikut hasil dari daur ulang sampah yakni:

Pertama, pembuatan baju plastik.

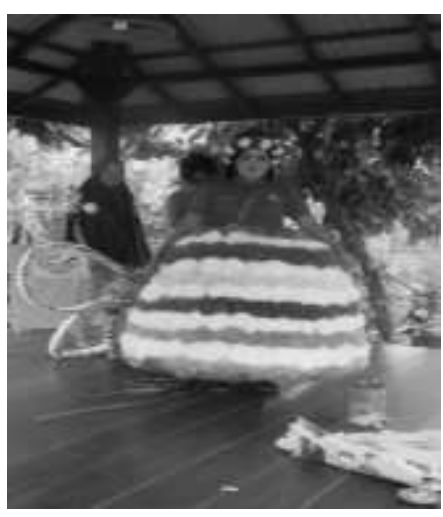

a

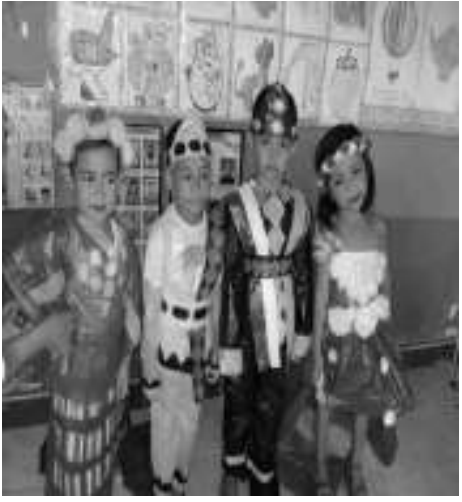

b

Gambar 4. (a) untuk dewasa (b) untuk anak

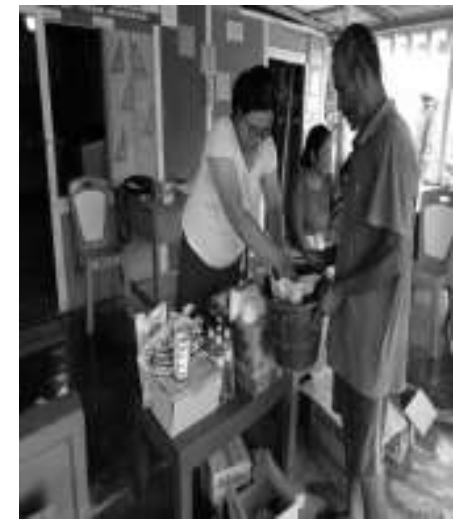

Gambar 5. Aktifitas sembako tukar sampah bersih

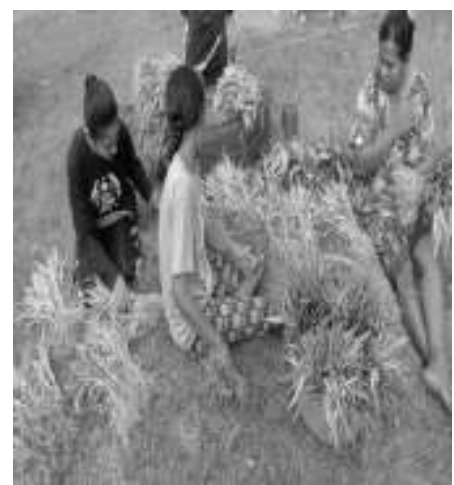

Gambar 6. Sampah ditukar dengan sayur organik 


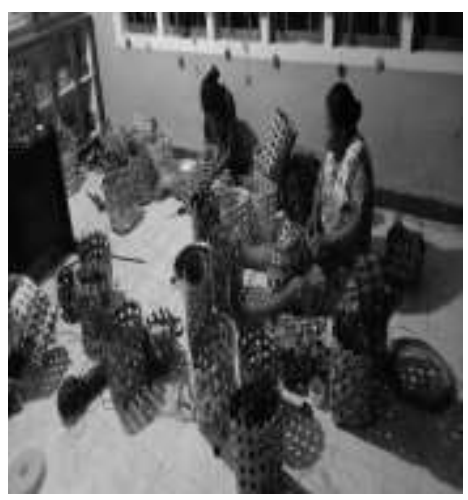

Gambar 7. Aktivitas pembuatan tas daur ulang

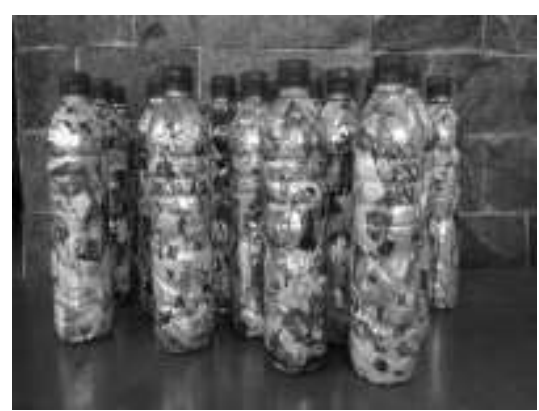

a

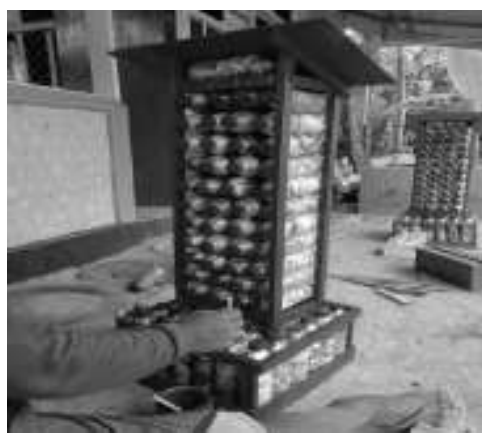

b

Gambar 8. (a) Eco brick sebagai pengganti batu bata (b) Mimbar yang dibuat dari eco brick

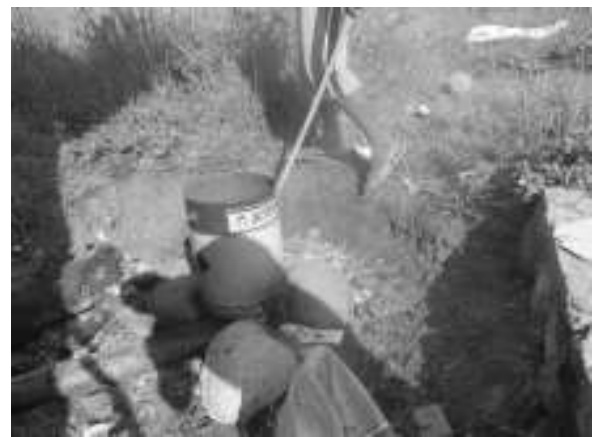

a

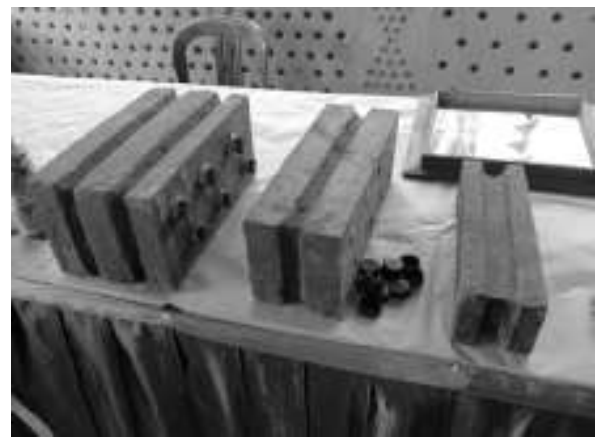

b

Gambar 9. (a) Aktivitas pembuatan paving daur ulang (b) Paving/Batako daur ulang

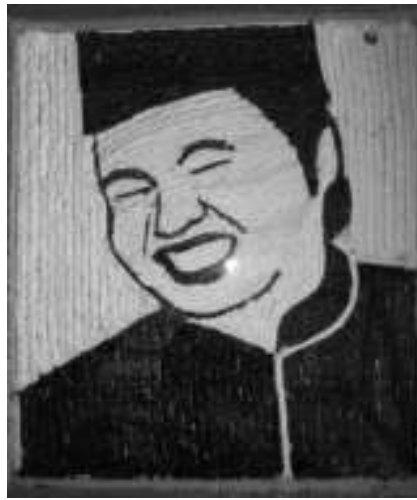

Gambar 10. (a) Lukisan dari kantong plastic bekas 


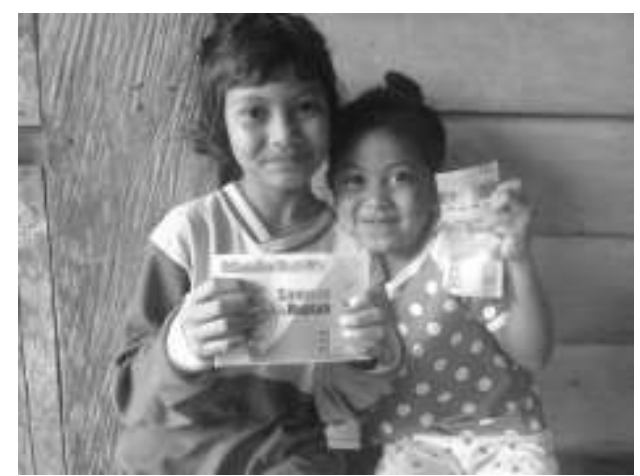

a

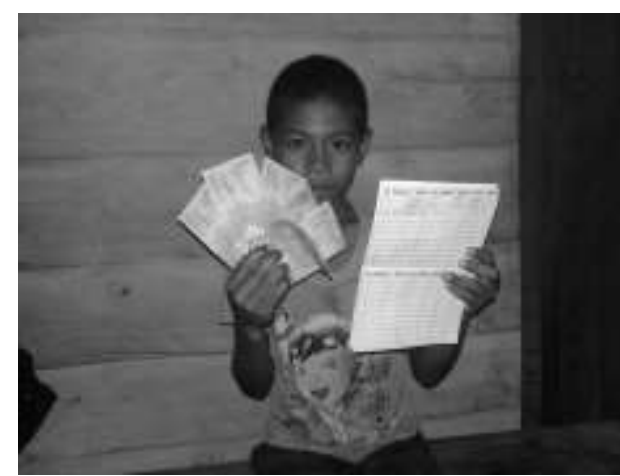

b

Gambar 11. (a) Aktivitas pencairan nasabah (b) Pencairan dana nasabah

Pendekatan partisipasi masyarakat dapat mendorong partisipasi masyarakat dalam pengelolaan sampah dari sumbernya. Masyarakat yang berdaya dalam pengelolaan dapat mengorganisir kegiatan bersama untuk memecahkan permasalahan sampah dan bentuk kesadaran menanggapi permasalahan sampah (Setiadi, 2015). Relawan dapat mensosialisasikan pemisahan sampah organik dan anorganik agar bisa dijadikan pupuk kompos dan didaur ulang. Pembuatan unit pengolahan kompos dengan melibatkan masyarakat setempat (Kosmanto et al., 2012).

\section{KESIMPULAN}

Berdasarkan hasil sosialisasi maka pengurus bank sampah membuat komitmen yakni:

1. Memperluas wilayah jangkauan penjemputan sampah oleh Bank Sampah Montolutusan.

2. Peningkatan jumlah nasabah.

3. Bank Sampah Montolutusan dan Bank Sulawesi Tengah akan bekerja sama untuk mengadakan tabungan pendidikan bagi nasabah, khususnya anak sekolah.

4. Peresmian Bangunan BSM Montolutusan ( $70 \%$ dari sampah ).

5. Peningkatan kualitas SDM pengurus BSU Montolutusan.

6. Meningkatkan sosialisasi kepada Masyarakat tentang pemilahan sampah dan proses daur ulang.

\section{DAFTAR PUSTAKA}

Arsyandi, M., Pratama, Y., \& Apriyanti, L. (2019). Perencanaan Sistem Pewadahan dan Pengumpulan Sampah Rumah Tangga di Bantaran Sungai Cikapundung Kota Bandung. Jurnal Serambi Engineering, 4. https://doi.org/10.32672/jse.v4i2.1464

Dai, S. I. S., \& Pakaya, S. I. (2019). Pemberdayaan Masyarakat Melalui Pengelolaan Sampah Menjadi Nilai Ekonomis dan Pembentukan Bank Sampah di Desa Pentadu Timur Kecamatan Tilamuta Kabupaten Boalemo. Jurnal Ilmiah Pangabdhi, 5(2), 110-118. https://doi.org/10.21107/pangabdhi.v5i2.6113

Intan Paradita, L. (2018). Pemilahan Sampah: Satu Tahap Menuju Masyarakat Mandiri Dalam Pengelolaan Sampah. BERDIKARI: Jurnal Inovasi Dan Penerapan Ipteks, 6(2). https://doi.org/10.18196/bdr.6245

Kosmanto, Y., Rohidin, \& Brata, B. (2012). Strategi Pengelolaan Sampah di Tempat Pembuangan Akhir Kabupaten Bengkulu Selatan Tahun 2012. Naturalis: Jurnal Penelitian Pengelolaan Sumber Alam Dan Lingkungan, 1 (1). https://ejournal.unib.ac.id/index.php/naturalis/article/download/5912/2872.

Luthfianto, S. (2020). Inovasi Limbah Sampah Plastik Dan Kulit Kopi Menjadi Paving Blok Di Desa Penakir Kecamatan Pulosari Kabupaten Pemalang. Dinamisia: Jurnal Pengabdian 
Kepada Masyarakat, 4(1), 176-185. https://doi.org/10.31849/dinamisia.v4i1.3577

Mahyudin, R. P. (2017). Kajian Permasalahan Pengelolaan Sampah Dan Dampak Lingkungan Di Tpa (Tempat Pemrosesan Akhir). Jukung (Jurnal Teknik Lingkungan), 3(1). https://doi.org/10.20527/jukung.v3i1.3201

Purwanto. (2019). Pengelolaan "Bank Sampah" Berbasis Masyarakat sebagai Alternatif Meningkatkan Ekonomi Warga RT 004/RW 09, Cikarang Utara-Bekasi. Academics in Action Journal, 1(1), 27-37. journal.president.ac.id/presunivojs/index.php/AIA/article/download/740/451.

Radityaningrum, A. D., Caroline, J., \& Restianti, D. K. (2017). Potensi Reduce, Reuse, Recycle (3R) Sampah Pada Bank Sampah 'BANK JUNK FOR SURABAYA CLEAN (BJSC)’. Jukung (Jurnal Teknik Lingkungan), 3(1). https://doi.org/10.20527/jukung.v3i1.3194

Rijati, S., Intan, T., \& Subekti, M. (2017). Sosialisasi Daur Ulang Sampah Sebagai Upaya Pengembangan Eko-Budaya di Lingkungan Desa Sayang Jatinangor Kabupaten Sumedang. JATI EMAS (Jurnal Aplikasi Teknik Dan Pengabdian Masyarakat), 1, 29. https://doi.org/10.36339/je.v1i2.45

Sahil, J., Al Muhdar, M. H. I., Rohman, F., \& Syamsuri, I. (2016). Sistem Pengelolaan dan Upaya Penanggulangan Sampah Di Kelurahan Dufa- Dufa Kota Ternate. Jurnal Bioedukasi, 4(2), 478-487. https://media.neliti.com/media/publications/89585-ID-sistem-pengelolaan-danupaya-penanggulan.pdf

Setiadi, A. (2015). Studi Pengelolaan Sampah Berbasis Komunitas pada Kawasan Permukiman Perkotaan di Yogyakarta. Jurnal Wilayah Dan Lingkungan, 3(1), 27-38. https://ejournal2.undip.ac.id/index.php/jwl/article/download/167/pdf.

Zahra, F., \& Damanhuri, T. P. (2011). Kajian Komposisi, Karakteristik, Dan Potensi Daur Ulang Sampah Di TPA Cipayung, Depok. Jurnal Teknik Lingkungan , 17(1), 59-69. https://ftsl.itb.ac.id/wp-content/uploads/sites/8/2017/03/6.-Fatimah-Zahra-TriPadmi.pdf. 